\title{
Engineering sustainable sewage systems
}

\author{
B. Rydhagen ${ }^{1}$, C. Dackman ${ }^{1}$, H. Åberg ${ }^{2}$ \& S. Jonsson ${ }^{3}$ \\ ${ }^{1}$ Technoscience Studies, Blekinge Institute of Technology, Sweden \\ ${ }^{2}$ Food, Health and Environment, University of Gothenburg, Sweden \\ ${ }^{3}$ Water and Environmental Studies, Linköping University, Sweden
}

\begin{abstract}
Urban sewage collection is part of an infrastructural system developed during the past century to increase convenience and hygienic standards in households. With the attention on sustainable development growing during the 1980s-1990s, Swedish municipal sanitation professionals began to pay attention to recycling of the nutrients in the sewage. The attempt in this paper is to draw together important thoughts from studies of professions, of communication and of sanitation and other infrastructural sociotechnical systems in an effort to better understand current efforts to increase sustainability in the sewage system in Sweden. It is argued that the momentum of a large sociotechnical system like the sewage network makes it difficult to change the system. However, with the focus on sustainability and on recycling of nutrients, sanitation professionals express an increased need to communicate with users and other actors, in order to reduce harmful substances in the system. In two Swedish municipalities, two different methods to improve the quality of the sewage were tried; source separation of toilet sewage water, and intensive information to households about proper use of the current system. In the former case, existing social and organizational structures were preserved, while the latter case caused increased collaboration with other municipal staff as well as households and other actors.
\end{abstract}

Keywords: sewage, sanitation, professionals, engineer, communication, sociotechnical system, household, user, sustainable development.

\section{Introduction}

Engineering has the advantage of being both a noun and a verb. It is an activity as well as a profession. Using it in both senses, we intend to discuss the ways 
professionals working with sewage systems handle the recognition of end user involvement in the reach for sustainability in the systems. This recognition has developed from the attention paid to the value of nutrients in sewage sludge, at the same time as an increasing number of chemicals are dispersed and detected in the same sludge.

Urban sewage collection is part of an infrastructural system developed during the past century to increase convenience and hygienic standards in households. Underground wastewater collection pipes were installed in urban areas by private and public actors (Jonsson et al [1]). At a later stage, treatment of the effluent wastewater was installed to reduce harm caused in recipient waters by biodegradable organic matter, phosphorus and nitrogen. The system has been under municipal control and management under strict national regulations, making it similar in the whole country.

With the attention on sustainable development growing during the 1980s1990s, Swedish municipal sanitation professionals began to pay attention to recycling of the nutrients in the sewage, and not only to regard the treatment process as a removal of unwanted substances (Söderberg [2]). Alternative sanitation technologies to collect nutrients were introduced in a number of pilot scale projects during the $1990 \mathrm{~s}$, including urine diversion and separate collection of toilet wastewater (e.g. Rydhagen [3]). These technologies shared the characteristic of changing the design of household installations. However, these pilot projects were not followed by further steps in this direction. Instead, we can see a focus on improving the quality of nutrient-rich sewage sludge emerging from the present combined waterborne sewage system. A main issue is to reduce the harmful substances entering the system from households and industries. Major efforts were done in a project called ReVAQ, where a number of stakeholders defined a number of standards and efforts required to allow spread of sludge on agricultural land (Kärrman et al [4]).

The sustainability of this method is debated. Actors from food industry, environmental groups and consumer groups, water and wastewater professionals and farmers' associations disagree on the threat posed by the content of heavy metals and household chemicals ending up in the sewage sludge. Nevertheless, alternatives to the combined, waterborne sewage collection are rare.

\section{Research questions}

The attempt in this paper is to draw together important thoughts from studies of professions, of communication and of sanitation and other infrastructural sociotechnical systems in an effort to better understand current efforts to increase sustainability in the sewage system in Sweden.

Questions in focus of the study are;

- How is the working role of sanitation professionals shaped and perceived?

- How do sanitation professionals perceive their relation to and communication with users?

- What changes in the relations and communication patterns do we identify as desirable in the move towards sustainable sewage systems? 
Our empirical material is focus group interviews and individual interviews with sanitation professionals and with those who educate the engineering students in two different regions in Sweden.

\section{Background and related research}

We use a number of departure points in this paper.

1. We assume that large infrastructural systems like the sewage system have developed a momentum, due to age, extension and specialized systems. This makes it difficult to change the system or shift to an alternative technological system.

2. We assume that a majority of sanitation professionals are trained as engineers, and that the profession embraces expert knowledge as well as certain status, routines and conceptions concerning the work. This shaping of professionals contributes to the momentum of an infrastructural system, as certain technological aspects are given privilege in education as well as work practices.

3. We assume that professionals shape and signal certain hierarchical structures in society, mainly that of knowledgeable professionals above unknowledgeable and/or uninterested users.

4. We assume that there is a shift in the sewage system from taking care of unwanted waste towards sustainable recycling of nutrients. This shift has placed an increased focus on the role of users as active participants in the sewage system. This, in turn, places new requirements on the work of the sanitation professionals.

5. Finally, we want to argue that the relation between professionals and users needs to change in order to achieve more sustainable sewage systems in line with the ambitions of the professionals.

In the following, we attempt to outline arguments for these assumptions, referring to different theories and studies in similar areas. The actual sustainability of the system is not discussed. Neither are factual actions and thoughts of users of the system included in this paper. Our focus is on the potential of the system from a professional perspective.

\subsection{Technological momentum}

Several researchers within the field of social studies of science (STS) have discussed the way sociotechnical systems take shape. Hegger [5] gives an extensive summary of different perspectives helping to understand possibilities and constraints to change towards sustainable systems. One important aspect of large sociotechnical infrastructural systems is that they tend to reach a state of momentum, resisting major changes in the basic structure (Hughes [6]).

Continued practice of combined, waterborne sewage collection despite the disadvantages of mixing and diluting nutrients with harmful substances is to a large extent due to the momentum of this particular sociotechnical system. The system was designed according to hygienic and convenience requirements, and 
many kilometres of pipes are buried underground in cities and towns. Treatment plants are designed to treat a mixed household wastewater, and engineers are educated to design and run the current treatment processes. In addition, households can expect an infrastructure that is almost identical in all urban areas in Sweden. Information and communication around the system between users and providers can be standardised to a large extent, and questions about user functions are minimal. Any kind of challenge to this system meets resistance for a number of reasons. Costs for new installations are a major argument against change. Another major argument is (assumed) willingness and competence among households.

Hegger [5] explores possibilities to test alternative technologies in niches, challenging existing solutions with technological innovations. The spread of niche trials to the larger regime depend on compatibility, but Hegger also argues that niches are important even if most of them do not spread.

\subsection{Demand management}

With a momentum regarding the technological aspects of the sewage system, reactions to problematic aspects of the system are sought for in the social context. Van Vliet [7] argues that demand management has become a new way of negotiating between users and suppliers of infrastructural services. The previous strategy, applied when the large infrastructural systems were developed, was supply driven to a large extent. More water was provided when the use increased, and additional sewage treatment steps were installed when new problems with discharge of nutrient rich waters arose. Today, instead of increasing supply when demand increases, utilities for different reasons try to influence user habits instead. Reasons for the changed strategy are for example limited access to water or the prospect of high investment costs if the demand continues to grow. Environmental requirements can also limit possibilities to adjust supply. As a new approach, the demand management challenges the momentum of infrastructure services slightly, placing new requirements on professionals to communicate with users, and on users to reflect on and change their habits.

Concerning sewage, it can be argued that because of an increasing number of chemicals ending up in the sewage although they cannot be degraded by the current treatment processes, sewage utilities need to work with demand management. There is a need to influence users to use and policy makers to limit permission to other or fewer chemicals that do not cause harm or that are degradable. This is a slight deviation from former supply thinking, where new processes were developed and installed to handle new requirements. Households become more visible and their cooperation more crucial for sewage professionals.

\subsection{The role of the sewage professional}

In a historical perspective, professions like engineering can be regarded as a discursive practice, where certain assets are required from those entering the 
profession. The training of engineers, as well as other professionals, contains expert knowledge on specific issues. Sanitation engineers learn how to design the sewage system from pipe networks to treatment processes. What is often missing in education programmes is the knowledge of how to run a project with negotiations with other professionals as well as other stakeholders (Torstendahl [8]).

In her research, Dovlén [9] confirms that professionals within different areas in the municipal sector show difficulties in communicating and negotiating with each other. In her case, environmental officers often fail to influence final decisions when economic matters are taken into account.

When the engineer enters the labour market, $\mathrm{s} / \mathrm{he}$ is in possession of a certain level of status as a professional. Although the engineers are trained to solve technical problems, their education is not only a way to gain knowledge about problem-solving, but as much to gain legitimacy and status in order to be trusted to the same problem (Torstendahl [8]). The hierarchical structure of professionalism and work conditions is likely to have a strong influence over the way communication around sewage issues between sanitation professionals and households or other actors take place.

As indicated above, the momentum of a sociotechnical system like the sewage system is partly due to the knowledge and abilities of professionals. In the current system, the roles of provider and user are rather well established. In Sweden, the provision of water and wastewater handling has been monopolised and is still strictly regulated as a municipal service. The professionals dealing with the provision are mainly engineers or natural scientists.

Along with the shift towards recycling of nutrients, new requirements on the professionals are placed. New substances are found in the sludge, at the same time as farmers' and consumers' trust in sewage sludge as a fertiliser is sought for. The individual professional needs to develop new skills and knowledge in a process of reflection in action (Schön [10]). When the work tasks cannot be solved within the current work description, the framework within which the work is defined needs to be renegotiated, both by the individual and within the organisation.

Inspired by Law [11] the concept of heterogeneous engineering has been elaborated in relation to the request for reflection (Rydhagen [12]). Recognition of multiple considerations for users, environment, technical aspects and finances increases the need for reflection in the practical work. This suggests that sanitation engineers need not only develop communication skills for better cooperation with other professionals. They also need to reflect on their own work tasks in relation to the goals with their work, and possibly reframe definitions of prioritised work.

\subsection{The relation between professionals and users}

We live in a time when scientists and engineers play a central role in the development and shaping of society. At the same time, there is a call for democratic decision-making about important technological developments like genetic engineering, energy systems and nanotechnology (Leach et al [13]). 
There is also a call for individual citizens to take their responsibility for the environment. Infrastructural systems are not an exception, especially since they often have an impact on the environment from local to global scale. Concerning the sewage system, debates about the use of sewage sludge on agricultural land open up arenas where professionals in different areas and users and other lay persons meet in new ways (e.g. Kärrman et al [4]).

Previous research with sanitation professionals (Rydhagen [3]) has indicated that the professionals regard households/users as a counterpart with little knowledge or interest in the sewage system and hierarchical terminology is in place. Professionals to a large extent describe the users/households as "those", not including themselves in the category. "They only want convenience" or "they know hardly anything about what happens after they flush" are expressions pointing towards a differentiation, almost dichotomisation between the subject professional and the end user. The task for the professional is to provide a robust system to satisfy the user without risking breakdown in case of minor misuse.

Hegger [5] refers to the (assumed) passive user as a citizen-consumer, but argues that users can take on (and be given) other roles in a more active sense. To begin with, Hegger argues that the dichotomy between production and use needs to be revised if users are going to be more integrated as actors in the sewage system. As Schön [10] argues, professionals ought to develop a dialogue with the user, being open about uncertainties and complexities. This, in turn, places new requirements on users too.

\section{Methods}

During the years 2006-2008, focus group interviews were done with municipal sanitation professionals in two cities in southern Sweden. The groups were formed to include persons involved in specific projects. In the first case, a technically modified sewage system had been installed in a new-built area. In the second case, intensive information directed to one specific area of housing had taken place concerning the sewage system. In the first case, two engineers, one communicator and one senior planner were interviewed. In the second case, the participants included one engineer, one senior engineer, one project assistant and the senior communicator. In the following, these cases will be referred to as "the technical project" and "the information project".

In addition, teachers at training institutes for sanitary engineers were interviewed at two technical universities in southern Sweden. At each institute, three persons were interviewed. Two persons were interviewed together at each place, while two other persons were interviewed individually. This was explained by the difficulty to gather all persons at the same time.

The interviews were approximately 1.5 hours each, were conducted by two researchers together, and were recorded and transcribed in full length.

Analysis of the interviews focused on discovering themes relevant to the research questions. Issues where the two municipalities expressed similar thoughts were identified, as well as issues where they expressed contrasting views or experiences. 


\section{Results}

\subsection{Framing the work}

At the training institutes for engineers, teachers confirm that their students end up in a variety of work positions. For some, the work is very specific concerning chemical processes or design of technical installations. For others, e.g. working in smaller municipalities, the work tasks are varied. The teachers emphasise that the engineering students need technical expertise knowledge, and they need to be problem solvers.

One of the sanitation professionals defined her work tasks as an engineer ranging from upstream chemical tracing to agricultural politics. On the other hand, most professionals agreed that they were not capable of doing all work tasks, but involved other professions such as municipal environmental inspectors and communicators within the same organisation. Within the technical project, the professionals stressed that the main focus was the technical components, while information need was not supposed to be extensive. In general information efforts in the municipality, market stalls were often manned by temporary consultants. In the information project the emphasis was on providing relevant information and to be available for communication with households. Hence, the permanent staff manned market stalls and visited the housing area when activities were planned there.

Teachers as well as professionals defined the chore of water and sewage work as sustainable development. Although the concept in itself was not in focus, recycling of nutrients and care for recipient waters was regarded to deal with sustainability issues in practice. At both the municipal offices, the extent of responsibility for sustainability resting on the water and sewage office was discussed. Since harmful chemicals end up in the sewage sludge or recipient waters, sewage staff reacts and take action in upstream work to reduce these chemicals. However, they find limited possibilities to take sole responsibility since this is a lifestyle issue that needs to be addressed in the wider society and by other actors.

In the information project, it was also mentioned that a few municipal politicians and employees at other departments had reacted negatively when the sewage department in local mass media recommended consumers to choose ecolabelled washing powder. It was regarded as a political statement unsuitable for a municipal department to express.

\subsection{Household relations}

The professionals in the two municipalities shared the view of households as rather uninformed, trusting and with little engagement in sewage issues. They also argued that households do not need to know much about the technical system, as long as they behave correctly and use the system in a wise way. None of the groups saw a need for increased user involvement in planning or decision- 
making, although they could give examples of this taking place in other fields of regional planning.

In the technical project, the professionals argued that the household members "fortunately have other things to think about" and hence, they should need to bother as little as possible about the sewage system. Still, the expectations on the households were that they act correctly. In the information project, one of the participants expressed surprise and disappointment over the lack of response from the households. The group working with the information project agreed on the need for feedback to the households, telling the results of the project.

As we raised the question of expectations between households and professionals in both directions, one of the professionals in the technical project argued that the expectations need to be reasonable in both directions. The professionals need to realise the limited engagement in sewage issues and be satisfied with proper behaviour, while the households need to realise that sewage treatment plants do not remove, degrade or disarm all kinds of chemical material.

\subsection{Contacts with other actors}

In close connection to the framing of the work lies the question of collaboration with other stakeholders or actors in society. The major focus in the research project is the communication between professionals and households, but other actors are also related to the engineering of sustainable sewage systems. In both municipalities, the interview participants mentioned the need for contact with and action from national authorities like the Environmental Protection Agency or the Swedish Chemical Agency when it comes to regulation of chemical substances in household products. In the information project, a number of projects focusing on local stores and shops were mentioned. Food stores as well as general stores and hair dressers had been addressed concerning the use and sale of environmentally friendly cleaning agents. This had lead to some shops taking out tooth paste containing antibacterial Triclosan, for example.

In both municipalities, partly competing interests were mentioned between municipal offices. Information activities were more focused on other areas like schools and childcare, or on solid waste rather than sewage.

In all these cases, the problem of drainpipe structure in the organisations was identified. This lead to competition and lack of collaboration, but it also lead to important issues falling between areas of responsibility. The problem with antibacterials such as Triclosan in toothpaste and other products, or silver in washing machines were mentioned as examples. These were not obvious responsibilities neither for municipal offices nor specific national authorities and therefore tended to be neglected.

The responsibility in the municipalities was regarded as a moral one, relating to the fact that this was where the problems appeared in the end.

\section{Discussion}

The technology project can be regarded as an example of what Hegger [5] calls a niche project, focussing on technological change with little attention to other 
aspects. On the other hand, the information project might be seen as demand management, with efforts to change the in-flow to the system, thus reducing the need for technological change. However, we also regard the information project as a niche project taking other than technical aspects into account. In this sense, the information project may function as an inspiration for other similar projects.

The advantages of the information project as a niche with aims (and possibilities) to spread are that the lay-out makes it possible to spread gradually, both content-wise and geographically. Large leaps are not necessary, since the changes do not depend on technical investments. This also allows for an extended period of flexibility and openness towards adjustments and unaccounted changes, which in turn facilitates maintaining the dynamics of sustainable development.

Another characteristic is that the information project requires changed relations within the municipal organisation - involving politicians and other offices earlier not active in the sewage sector. Relations with other actors in society, e.g. local shops and industry as well as households are brought into focus. These changes in relations may slow down the process, since other actors may not be prepared to take their roles in the new regime. Schön [10] argues for a more equal-level dialogue, but Dovlén's [9] experiences show that this does not occur automatically.

The interviews revealed a view among professionals of households that agrees with what Hegger [5] calls the consumer-citizen, common in large infrastructure systems. It has been the norm for about a century to assume the roles of provider and consumer, respectively. As was also mentioned in the interviews, there seem to be little interest among either households or professionals to change this relation. This view was shared by the participants in all focus group interviews.

However, as the information project in particular shows, the work towards sustainable sewage systems still imposes changes in the work tasks of the professionals. The focus on information in general increases, although the technical project aimed to reduce needs for information.

It seems that staff in the technical project preserved a distance between professionals and other actors, including households, while the information project had made necessary increased efforts to collaborate with households as well as other actors locally and nationally.

Paradoxically, thus, it can be said that efforts to maintain and improve the existing infrastructure has caused more changes for the professionals than a technical innovation has done. The heterogeneity of the work was acknowledged by the interview participants in the information project to a larger degree.

In the strive for more sustainable urban sewage systems, improving possibilities to recycle nutrients without jeopardising soil quality, we regard this approach as an innovative way. The narrow focus on technical solutions needs to be complemented by communication skills and efforts. The hierarchical social structure still needs to be challenged by the professionals in order to reach more active and engaged citizens. 


\section{Acknowledgements}

The research project was financed by Formas, which is hereby acknowledged.

\section{References}

[1] Jonsson, D., Gullberg, A., Jungmar, M., Kaijser, A. \& Steen, P., Infrasystemens dynamik - om sociotekniska förändringsprocesser och hållbar utveckling, Avdelningen för teknik- och vetenskapshistoria, KTH, Stockholm, 2000.

[2] Söderberg, H., Kommunerna och kretsloppet, Linköping University Dissertation: Linköping, 1999.

[3] Rydhagen, B., Boendeaspekter på resurseffektiv hantering av svartvatten och organiskt hushållsavfall. VA Forsk Report 2003-2: Stockholm, 2003.

[4] Kärrman, E., Malmqvist, P-E., Rydhagen, B. \& Svensson, G., Utvärdering av ReVAQ-projektet, Svenskt Vatten Utveckling Report 2007 - 02: Stockholm, 2007.

[5] Hegger, D., Greening Sanitary Systems: and End-User Perspective, Wageningen University Dissertation: Wageningen, 2007.

[6] Hughes, T.P., Networks of Power. Electrification in Western Society, 18801930, John Hopkins University Press: Baltimore, 1983.

[7] Van Vliet, B., Chappells, H. \& Shove, E., Infrastructures of Consumption: Restructuring the Utility Services, Earthscan Canada: Toronto, 2005.

[8] Torstendahl, R. \& Burrage, M., (eds). The Formation of Professions. Sage Publications: London, Newbury Park and New Delhi, 1990.

[9] Dovlén, S., Communicating Professional Perspectives, KTH Dissertation: Stockholm, 2005.

[10] Schön, D., The Reflective Practitioner. How Professionals Think in Action. Ashgate Arena: Aldershot, 1995.

[11] Law, J., Technology and heterogeneous engineering: the case of Portuguese expansion, The Social Construction of Technical Systems: New Directions in the Sociology and History of Technology. eds Bijker, W., Hughes T. \& Pinch, T., MIT Press: Cambridge, Mass, pp. 111-134. 1987.

[12] Rydhagen, B., Feminist Sanitary Engineering as a Participatory Alternative in South Africa and Sweden, Blekinge Institute of Technology Dissertation: Karlskrona, 2002.

[13] Leach, M., Scoones, I. \& Wynne, B., (eds). Science and Citizens, Zed Books: London and New York, 2007. 